\title{
A baseline method for benchmarking mortality losses in Atlantic salmon (Salmo salar) production
}

Silvia Soares $^{1}$, Darren M. Green ${ }^{1}$, James F. Turnbull ${ }^{1}$, Mags Crumlish ${ }^{1}$, Alexander G. Murray ${ }^{2}$

\author{
${ }^{1}$ Institute of Aquaculture, School of Natural Science, University of Stirling, Stirling, FK9 4LA, United \\ Kingdom. \\ ${ }^{2}$ Marine Scotland Science, Marine Laboratory, Victoria Road, P.O. Box 101, Aberdeen, AB11 9DB, United \\ Kingdom. \\ *Corresponding Author: tel.: +44 (0) 1786 467874, fax: +44 (0) 1786 472133, e-mail: s.m.soares@stir.ac.uk
}

Key words: Fish health, benchmark, on-farm database, mortality records

\begin{abstract}
On-farm databases provide a large diversity of information regarding fish health and stock performance. Mortality records held in on-farm database are indicators of fish health status and of great interest for studying fish health, such as patterns of diseases. Mortality records from a Scottish Atlantic salmon production database of one company were used to develop a method of benchmarking production losses due to mortality. The records used concerned mortality loss numbers of Atlantic salmon in the seawater phase. The median, 10th and 90th percentiles of mortality were calculated for each week of production from 88 production recorded cycles. These values were used to delimit the range of a standard mortality curve through the production cycle. The effects of the different mortality losses from each cycle on production in terms of costs and time consumed were also described. Likewise, substantial interannual variation in mortality time series is described as well as the mortality variation associated with three diseases (Pancreas Disease, Cardiomyopathy Syndrome and Infectious Pancreatic Necrosis).
\end{abstract}

\section{Introduction}

Scotland is the largest producer of farmed salmon in the EU and the third largest producer in the world, after Norway and Chile (Anonymous, 2009 a); recently Chilean production has declined substantially owing to disease problems (Anonymous, 2009b), notably outbreaks of infectious salmon anaemia (ISA) (Mardones et al., 2009) and parasite induction problems (e. g. sea lice) (Gustafson et al., 2005, Nylund et al., 1993, Vass, 2010). Within the UK, 
Scotland is the main source of salmon and is responsible for $80 \%$ of UK aquaculture production (Anonymous, 2009 a).

Farmed salmon, as with other cultivated species in aquaculture, face the problem of diseases. They are a huge constraint to aquaculture industry development (FAO, 2007), and losses caused by various diseases represent a substantial proportion of loss costs in salmon industry (Menzies et al., 2002; Brun et al., 2003, Skall et al., 2005). Therefore disease control is crucial to the profitable production of any farmed species (Menzies et al., 1996).

Presently, the majority of salmon producers use sophisticated IT software as a tool in production control and inventory accounting (Aunsmo et al., 2008), with computerised record systems at the farm level to facilitate data collection. The introduction of these programs has been of great importance in facilitating the monitoring of health data, including causespecific mortality (Aunsmo et al., 2008). Fish weights, feed intake, fish movements, temperature and other environmental parameters and mortality numbers and biomass are examples of records found in fish production databases. This information has the potential to usefully inform health status of farmed fish as well as to give a comprehensive overview of the current production or production trends. Thus, the study and analysis of mortalities (patterns of losses and their causes) may provide more details of a particular disease, such as disease risk factors and seasonality.

Hammel and Dohoo (2005) in a study to investigate and describe the mortality patterns attributed to infectious salmon anaemia virus (ISAV) reported that initial outbreaks of infectious salmon anaemia (ISA) were relatively low (median of $<7 \%$ total mortality) when salmon were most likely naïve to ISAV with outbreaks exceeding $30 \%$ of total cumulative mortality. In Scotland the prevalence of infectious pancreatic necrosis (IPN) in post-smolt Atlantic salmon increased from $1.2 \%$ in 1990 to $12.5 \%$ in 2002 and the mortality at sites with confirmed IPN varied between $0.03 \%$ and $0.1 \%$ per day in May and $0.5 \%$ per day in July (Bruno, 2004). More recently, Mardones et al. (2009) found that roughly $20 \%$ of farms at risk of ISAV in Chile became infected with the virus, with the incidence of ISA increasing slightly over time. Moreover, epidemiological studies of mortality in relation to site management practices may also be carried out to explain the effects of these practices on mortality rates in farmed Atlantic salmon (Wheatley et al., 1995). 
Mortality records have been used for the development of methods for benchmarking production mortality losses, in terms of numbers or biomass and are recognized as valuable tools for fish farmers (Anonymous, 2009 c). For instance in the trout (Anonymous, $2009 \mathrm{c}$ ), dairy (Khade and Metlen, 1996), sheep (Geenty et al., 2006) and pig (Davidson, 2005) industries.

Benchmarks may also be used to identify unusual patterns of mortality before serious loss has occurred, and thus allow management actions to pre-empt a problem. For example, in poultry (Frost et al., 2003, Stacey et al., 2004), pig (Parsons et al., 2007) and diary cow (Frost et al., 1997) industries, systems for collecting real-time data have been developed for controlling growth, health and reproduction (Frost et al., 1997).

These systems allow collection and analysis of a huge variety of information of on-farm data including mortality and production records (Frost et al., 1997). Additionally, these systems also look for deviations between actual production results and the ones expected (Frost et al., 1997). These deviations are examined for statistical and economical significance (Frost et al., 1997). Therefore, real-time data sources are of great value for monitoring growth, health and reproduction. Benchmarking is also important in health management for tracing and tracking diseases in salmon production. In addition, this approach could also be a useful tool for designing research concerning fish welfare, production, health and treatments and for informing governmental policies. Furthermore, the benchmark approach also allows the investigation of costs and profitability of salmon production. The Canadian salmon industry (Anonymous, 2006) is an example of a benchmark study that compares the performance of the Canadian farmed salmon, industry against the performance of the Norwegian and Chilean farmed salmon industries in the US market.

The aim of this work was to develop a baseline method of benchmarking weekly mortalities of farmed salmon as an indicator of health status and a method of diagnosing early production problems. Moreover, the main types of mortality causes across production cycles were quantified. 


\section{Material and methods}

\subsection{Data collection}

The data were supplied from a single company and included over 60 million Atlantic salmon smolts that were moved into 82 marine production sites located on the western coast of Scotland (Kilburn, R.; Soares, S.; Murray; S., unpublished results). Production cycles between the years 2000 and 2006 were analysed, with only complete cycles of salmon production included. Production data for mortality causes, mortality losses, smolt input and harvest data were extracted from a BusinessObjects ${ }^{\mathrm{TM}}$ database. (Kilburn, R.; Soares, S.; Murray; S., unpublished results).

\subsection{Mortality data}

\subsubsection{Daily mortality}

Cage-level daily mortality was recorded as the number of dead fish retrieved by different methods (e.g. divers, hand hold baskets for dead fish removal, lift-up collectors and hand nets). On days were either zero mortality was recorded or no records of mortality were present it was assumed that no dead fish were removed on that day. In such cases, the following day's mortality was evenly allocated between the preceding days of non-retrieval for the purpose of analysis (Hammel and Dohoo, 2005; Ansumo et al., 2008).

Daily weekly mortalities were expressed as a percentage of fish on site at the end of the week. The mortalities of the seven days were averaged and considered the mean mortality at the end of the week. The day of transfer of first fish into the site was considered day zero. All the others transfers into and out of site were not a problem as the number of fish used for calculating the mortality percentage on site was the adjusted number of fish on site. In addition, the transfers between cages on a site also were not a problem since the cycle on site was the study unit. 


\subsubsection{Cause of death}

Mortality in the database was attributed to one of the 52 pre-assigned causes. Those 52 causes of death were grouped into five categories (Table 1): disease, production, environment, predation and unknown causes. The pre-assigned causes are written in italic every time each of them is referred in the text. Those causes of death might have been attributed by a farmer. There was no information of which methods (such as veterinary diagnostic tests) were used to assign the causes to dead fish in the database. Concerning IPN, two codes were attributed to distinguish among suspected and confirmed outbreaks of IPN. Therefore, when IPN is referred to below as being positive it means that the cycles used the confirmed outbreak code. The remaining codes for diseases did not distinguish among suspected and confirmed outbreaks, except PD that was coded as suspected. Therefore, every time a cycle has assigned one of the other remained codes, it was considered as positive for that disease code. 
Table 1. Mortality causes of the database studied grouped in five groups of causes. The percentages (\%) of each disease by total number of fish lost are represented as: *, $0.5 \% ; * *, 0.5-1 \%$; ***,> $2 \%$.

$\begin{array}{llll}\text { Unknown } & \text { Production } & \text { Diseases } & \text { Environment } \\ \text { Blind } & \text { Accident loss } & \text { Bacterial kidney disease (BKD)** } & \text { Environmental } \\ \text { Decomposed } & \text { Caught in net } & \text { Cardiomyopathy (CMS)** } & \text { Jellyfish } \\ \text { Deformed jaw } & \text { Cull } & \text { Fin rot*** } & \text { Oxygen Starvation } \\ \text { Disappeared } & \text { Failed smolts } & \text { Fungus* } & \text { Plankton bloom } \\ \text { Event mortality } & \text { Jacks } & \text { Infectious pancreatic necrosis (IPN)*** } & \text { Storm } \\ \text { Eye damage } & \text { Mature } & \text { Moritella* } & \text { Predation } \\ \text { Gill damage } & \text { Net tear } & \text { Pasteurelosis* } & \text { Birds } \\ \text { Lesion } & \text { Normal } & \text { Rickettsia (SRS)** } & \text { Mink } \\ \text { Option missing } & \text { Parr } & \text { Sea lice* } & \text { Seals } \\ \text { Other } & \text { Precocious male } & \text { Suspected furunculosis* } & \\ \text { Physical damage } & \text { Transfer } & \text { Suspected infectious pancreatic necrosis (Suspected-IPN)*** } \\ \text { Runts } & \text { Treatment kill } & \text { Suspected pancreas disease (PD)*** } & \\ \text { Samples } & \text { Smolt transfer } & & \\ \text { Sample weighing } & \text { Suspected cannibalism } & \\ \text { Unidentified } & & \end{array}$

\subsection{Statistical analysis}

A benchmark curve of losses recorded in the database was developed. For that, the median, 10th and 90th percentiles were calculated as percentage per day for each week of the production cycle on site. These percentiles were based on the distribution of weekly mortality between all the production cycles for the given week since the production cycles commenced. The median was chosen as the central line of comparison of the standard curve of mortality due to not being influenced by extreme values of mortality and the 10th and 90th percentiles were used to delimit the range of a standard mortality curve through the production cycle. The first week of the cycle was considered the start point of the time series. Time zero was considered the day that fish was moved into the site. The other transfers, in and out of the site, were not a problem for the benchmark as the adjusted numbers of fish on site were used. Transfers between cages on a site also were not a constraint for the time series because the cycle on the site was the unit of study.

\section{Results}

\subsection{Database description}

In this study, the production cycle was considered the study unit instead of the site. A production cycle is the time between input of fish onto a marine site and their removal for harvest. Mean cycle time was 89 weeks, but this varied from 54 to 124 weeks. Sites start their production cycles throughout of the year and as a result, the times on the benchmark curve for median mortality refer to a specific time after input not to time of year. Thus, the 
pens/cages belonging to the site were not individually considered as the cycle on site was the study unit. A total of 83 sites and 157 cycles in the database were recorded. Therefore, 157 cycles were considered instead of 83 sites (35 sites had one production cycle, 22 sites had two production cycles and 26 sites had three production cycles). From these 157 cycles, only 88 were analysed. Of 69 cycles excluded, 31 production cycles were of halibut, while four were from experimental units and so not appropriate for analysis of commercial salmon production cycles. An additional three cycles were from sites with continuous production that lacked discrete production cycles. Of the remaining 31 cycles, 25 were excluded because data were incomplete (lack of mortality records at least during the first seven months after fish moved in, abnormal inputs of one or ten fishes and no records of input numbers and fish species), while six cycles had a cycle length of less than nine months.

\subsection{Description of studied population}

The 88 production cycles included in this study encompassed over 44 million Atlantic salmon in the marine stage between the years 2000 and 2006. Production cycles that were not complete at the end of the data records in 2006 were not included in this study. The initial range of fish weight at the site level was $45-100 \mathrm{~g}$ and the mean range of weight of fish harvested was $4.5-5 \mathrm{~kg}$. The total mortality percentage from the input until the end of the production cycle of the population studied was $24 \%$.

The main categories of losses observed in the studied database were disease with $31 \%$ of numbers of fish lost; production factors with $29 \%$, the environmental group and predation with $8 \%$ and $7 \%$ respectively and finally a group of unknown causes with $26 \%$ mortality. Figure 1 shows the percentage mortality in each group across the weeks of the production cycle. The main causes of losses at the beginning of the production cycle were diseases followed by production-related mortality. The mortality decreased over time. However, around week 70 was observed a second peak of mortality due to disease causes (Fig. 1). Losses due to the unknown group were observed in a continuous percentage throughout the weeks of production cycle (Fig. 1). Mortality losses caused by predation and environment groups were observed in small percentages along the weeks. However, environmental factors caused a first peak of mortality around week 43 due to storm events. In this week, an extreme mortality event of $16 \%$ was observed in one of the production cycles. This represents $0.5 \%$ of the total number of losses recorded. The second peak of mortality observed from week 47 
to 50 is caused by plankton bloom. In week 48 and 49 , the average mortality was respectively $1 \%$ and $4 \%$ of the total number of losses recorded (Fig. 1).

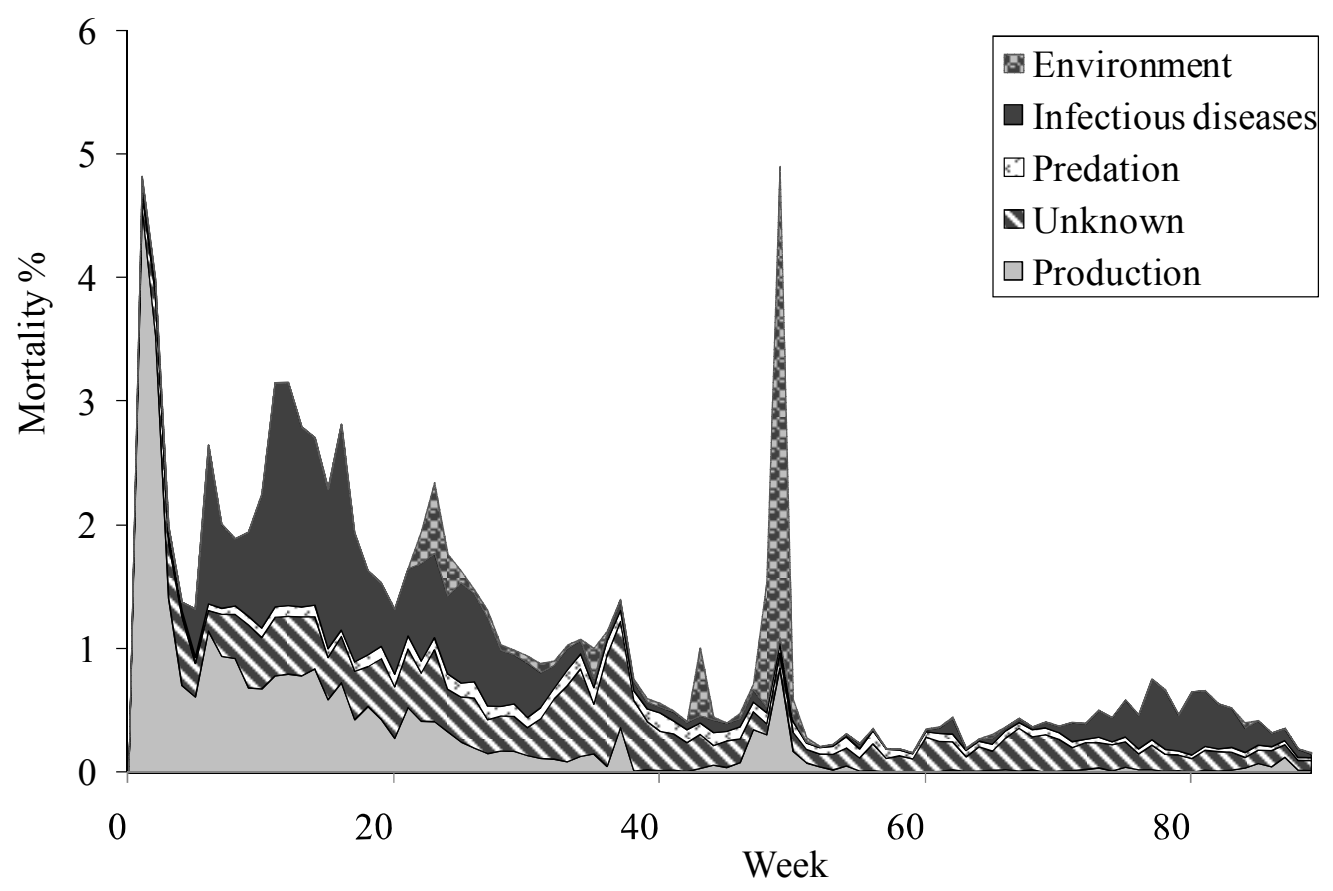

Fig 1. Percentage of losses by the total number of losses of all causes across the weeks of production cycle of the population studied. The mortality causes were grouped in five categories (environment, diseases, predation, unknown and production).

\subsection{Mortality benchmarking curve}

A standard mortality curve was developed for assessing variation in mortality rate between and within sites during the life-cycle of the population studied (Fig. 2). This curve allows benchmarking the mortality percentage of fish on site across the weeks of production.

In Fig. 2, the graph shows a decline of median mortality in the first weeks after stocking. Then an increase in mortality is observed until week 19 and from this week onwards the mortality percentage reduced gradually. The peak of mortality observed in the first week in Fig. 2 is caused by production factors, as seen in Fig. 1, mainly by transfer and failed smolts. After week 5, the mortality increases again due to disease problems (Fig. 1) attributed mostly to IPN until week 19. 


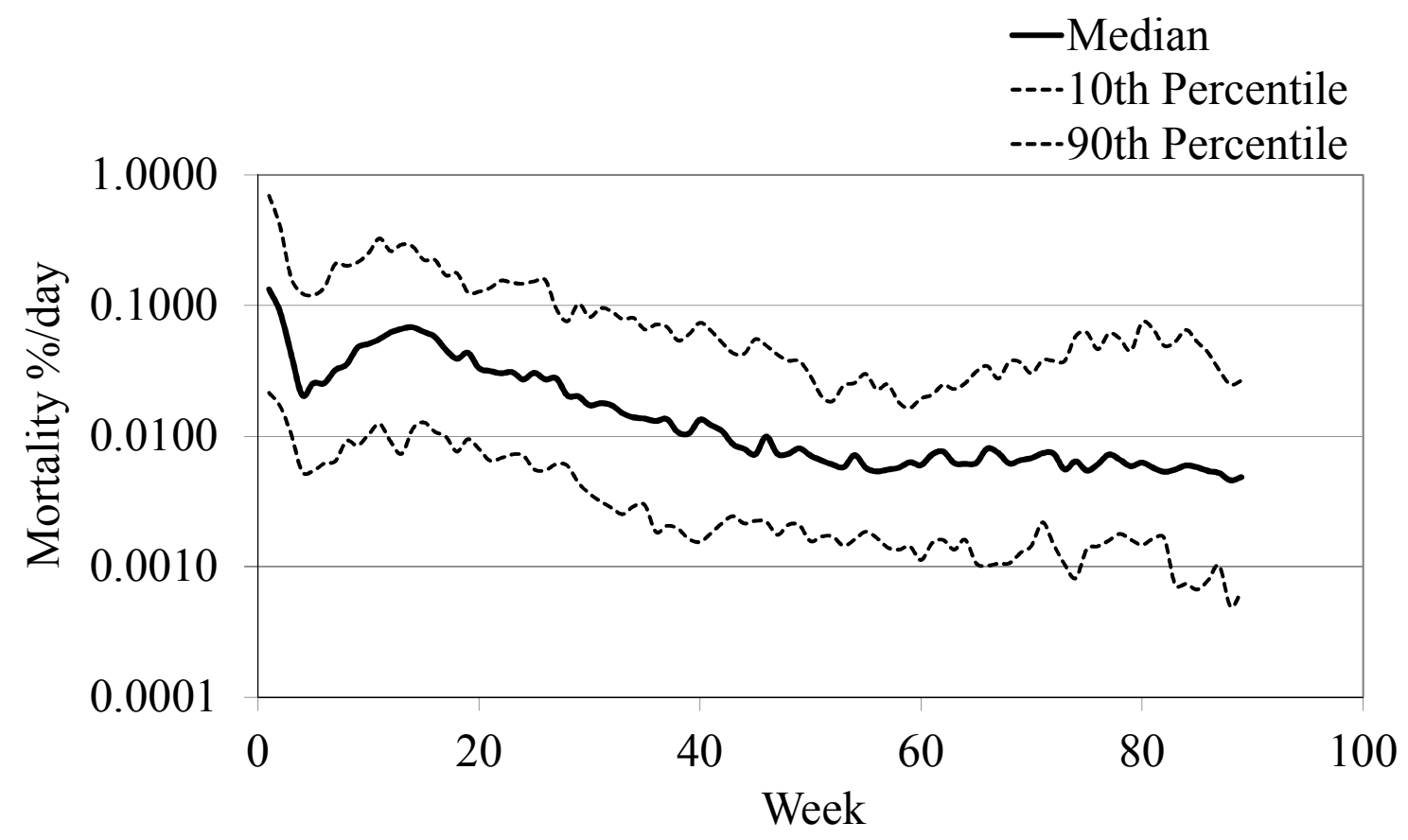

Fig. 2. Standard mortality curve of daily mortality. 10th, 50th and 90th percentiles of weekly mortality are shown, rescaled as daily mortality rates.

\subsection{Benchmarking mortality of cycles}

Fig. 3 shows a comparison of daily mortality averaged per week from four different production cycles with the standard mortality curve superimposed. Cycle (a) represents a production cycle, with daily mortality averaged per week, following close to the standard mortality curve, while (b) and (c) shows two cycles with the mortality percentage under and above the standard mortality curve, respectively. Finally, cycle (d) represents a production cycle with an increase of the percentage of weekly mortality at the end of production. 

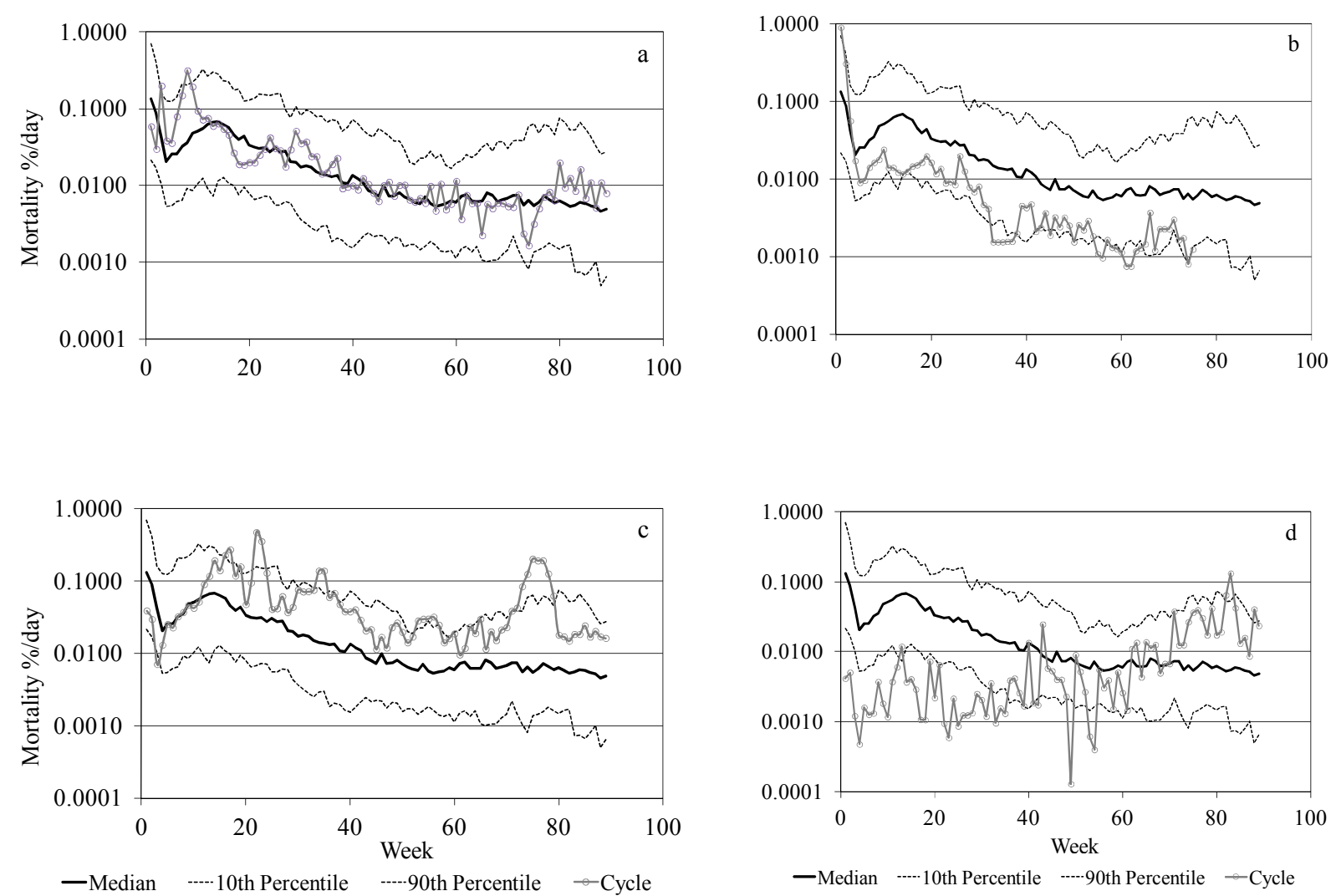

Fig 3. Benchmarking five different mortality time series with the standard daily mortality curve of the population studied. Production cycles show mortality close to the median (3a), persistently low mortality (3b), persistently high (3c) and low early, becoming high (3d).

\subsection{Benchmarking interannual mortality variation}

Fig. 4 shows the interannual variation in median mortality of production cycles. In this study, the year corresponds to year of the start of each production cycle and not to the calendar year. Only cycles beginning in 2001, 2002, 2003 and 2004 were considered. Cycles beginning in 2000 and 2005 were not included because there were too few cycles in these years to perform a statistically viable analysis. Although the database contains mortality records from the calendar year 2006, these were from cycles that commenced in 2005 and so there are no 2006 cycles. For 2001 to 2004, weekly median mortality was compared with the standard mortality curve across all years. In 2002 and 2004, the mortality curve followed closely the standard mortality curve. In 2001, the mortality had a peak of $15 \%$ of the total number of losses recorded in week 49 due to plankton blooming. This value did not show on the standard mortality curve because the median was used instead of the mean. The median is a non parametric measure and it is not sensitive to extreme values. Apart from week 49, 2001 had lower percentage of mortality when compared to 2002, 2003 and 2004. In 2003 was observed 
a high mortality loss from week 26, when compared to 2001, 2002, 2004. The main causes of mortality were due to unknown causes with the maximum of mortality percentage ranging between $1.0 \%$ and $2.6 \%$ of the total losses recorded and diseases with a maximum mortality of $0.73 \%$ of the total losses recorded.

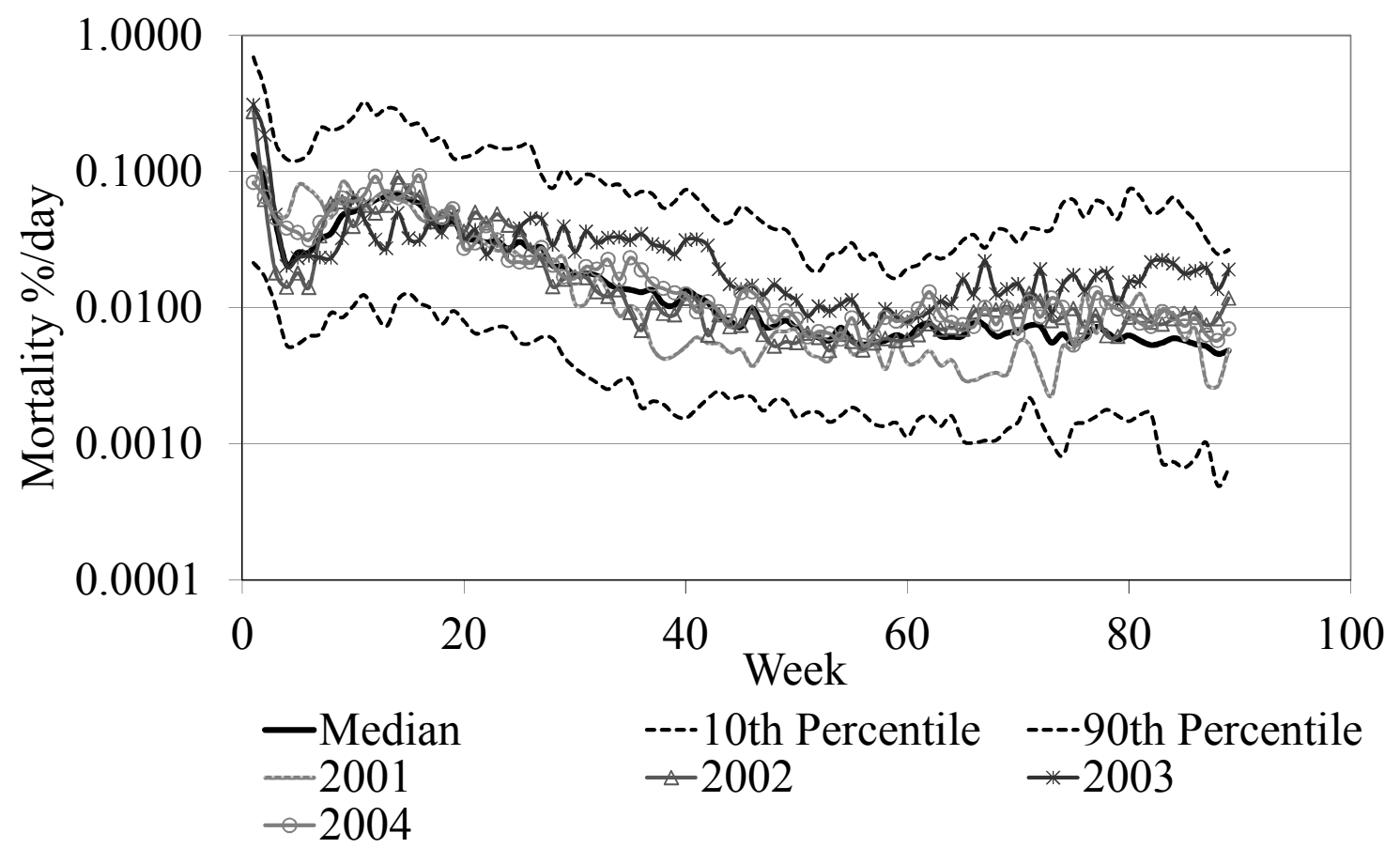

Fig 4. Benchmarking interannual variation in the median daily weekly mortality.

\subsection{Benchmarking pancreas disease, cardiomyopathy syndrome and infectious pancreatic} necrosis over weeks of cycle production

Fig. 5 and 6 show variation in the median mortality across mortality causes. In Fig. 5, the mortality time series from cycles suspected to be positive to $P D$ and cardiomyopathy syndrome (CMS) were represented. An increase in mortality was observed in both $P D$ - and $C M S$-positive cycles throughout the latter part of the cycle. $C M S$-positive cycles showed a slightly higher mortality in the latter part of the cycle when compared with the $P D$-positive cycles. Moreover, both $P D$ and $C M S$ showed an elevated mortality in the first four to six months. The similarity in timing of the two mortality causes is not surprising because both diseases have similar clinical signs. Cycles with clinical signs of $P D$ and $C M S$ were considered as suspected of $P D$ and $C M S$ in the database studied due to the similarity of both diseases. Fig. 6 shows a comparison among $I P N$-positive cycles and $I P N$-negative cycles. In $I P N$-positive cycles a slightly higher mortality percentage is observed in the first 40 to 50 
weeks, while in the $I P N$-negative cycles the mortality losses observed were slightly lower than the standard mortality curve.

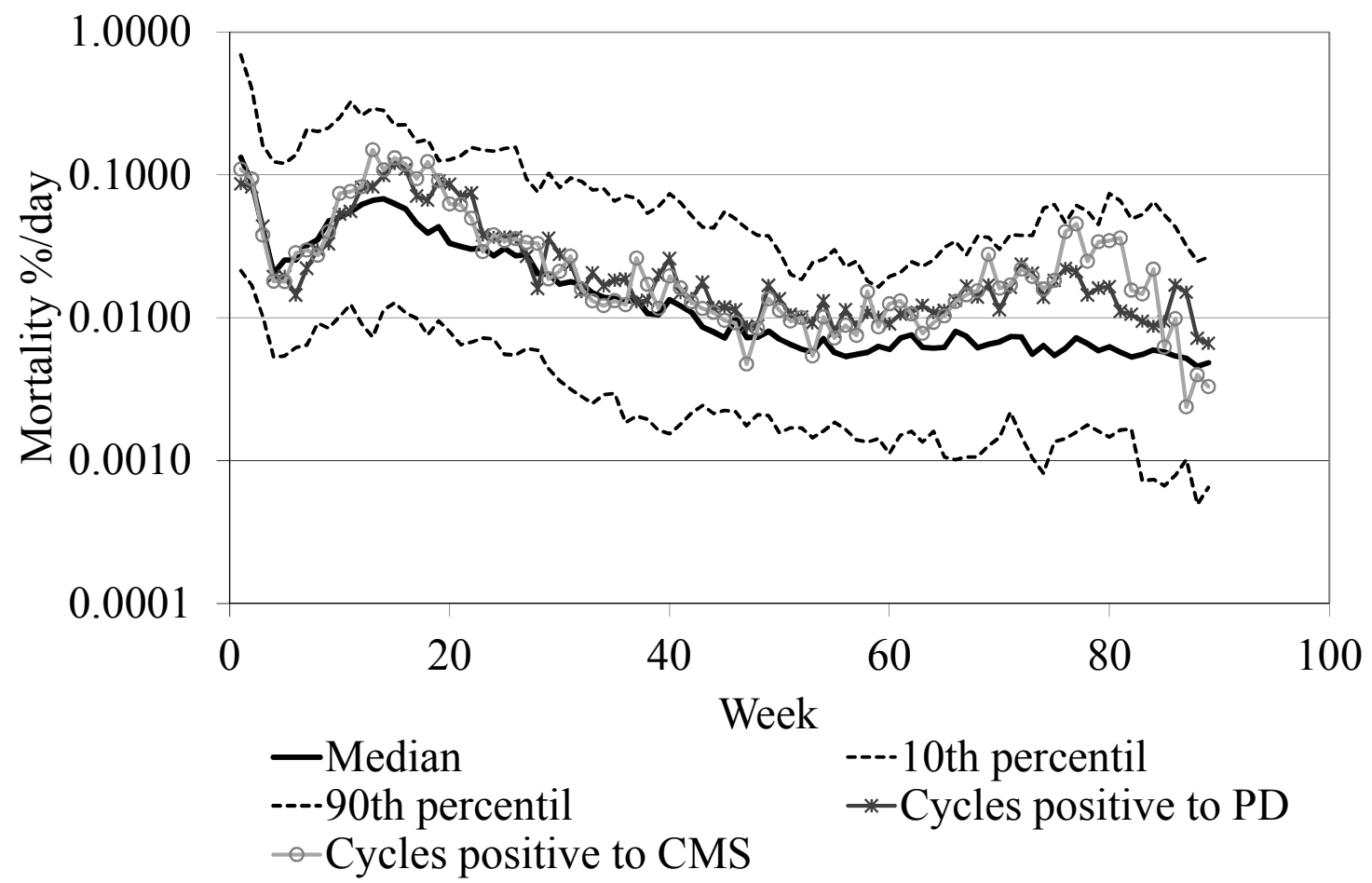

Fig 5. Benchmarking the PD and CMS mortality time series with the standard mortality curve over 89 weeks.

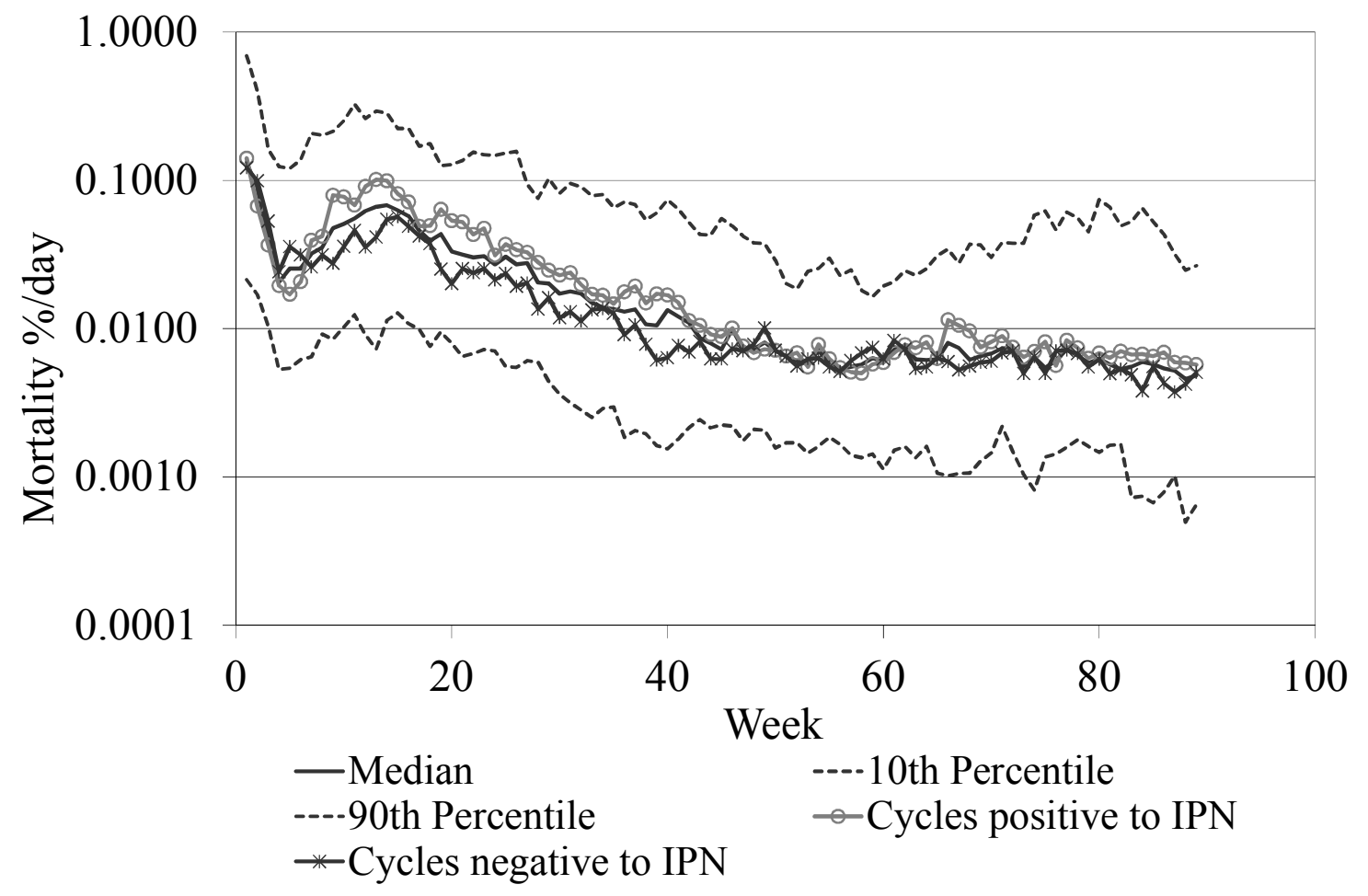

Fig 6. Benchmarking IPN daily mortality time series with the standard mortality curve over 89 weeks. 


\section{Discussion}

The aim of this study was to develop a baseline method for benchmarking of mortality losses in salmon production at seawater stage. For that, a database from 2000 to 2006 of one company was studied. Variations on the median of the standard mortality curve of the population studied caused by IPN, PD and CMS and the interannaual variation among the years 2001, 2002, 2003 and 2004 were investigated.

In this study only $56 \%$ of the cycles were used. Forty four percent of cycles held in the database were not included in the analysis. The main reason was due to the data pertaining to non-salmon species, experimental sites or sites with continuous production (24\%). These sites were excluded because they were not representative of commercial sites of farmed Atlantic salmon and therefore not relevant to the analysis. The $20 \%$ of cycles excluded from the analysis to avoid biased results caused by missing data and errors on records in the database. Other difficulty was concerns the missing data and the zeros recorded in the database. There was no information indicating the difference between these. Therefore, we assumed that the days with missing records meant that dead fish were not collected on that day, while the days with a zero recorded meant that the dead fish collection resulted in zero on that day. Additionally, in this analysis there was also a difficulty regarding the codes assigned to the different causes of mortality, as seen in table 1 . There was no information how these codes were attributed and how diseases were differentiated. Moreover, the codes regarding diseases did not suggest either suspected or confirmed disease conditions. The only exception was regarding infectious pancreatic necrosis, that was codified for suspected and confirmed outbreaks, and pancreas disease, which was classified as suspected. Thus, in the database there was no possibility to know when diseases or other codes were considered suspected or confirmed. Furthermore, it was suspected that great majority of causes were assigned by the farmer at the farm level.

One major limitation of this study regarding the ability to produce a benchmark applicable to all industry was that the data were restricted to a single company in the west coast of Scotland. However, this study may be used within the company as a tool to compare its production between sites (units) or group of sites. The possibility of benchmarking losses during the cycle or at the end will give the opportunity to allow the farmer to observe the impact of mortality losses on the production costs such as feed input and time spent of each 
cycle. The results from this work showed five different production cycles with different mortality curve patterns. Cycle (c) and (d) might be higher in terms of production costs including feed costs, than in cycles (a) and (b). The high mortality losses are observed in the second half of the production cycle, when fish are heavy and large and therefore the cost in terms of feed and time are higher than at the beginning of the production cycle. The results from the analysis performed in this study showed that the impacts of 2001 and 2003 in the fish production are different, when compared with 2002 and 2004 that followed the standard mortality curve. The mortality losses in 2001 were under the standard mortality curve from week 35, while in 2003 the opposite was observed. Consequently, 2003 might have had higher costs regarding feed input and time consuming because the heavier and larger fish were affected. Hence, studies concerning the impact of mortalities in the production costs may also be carried on in future, as seen in the study of mortality rate of calves and its effects on three levels of production (feed, milk and cheese) made by Khades and Metlen (1996) in the dairy industry. Likewise, studies regarding the direct cost of losses of production caused by a disease may also be performed as described by Menzies et al. (2002) and Brun et al., (2003) for cataracts and cardiomyopathy syndrome problems in Atlantic salmon production.

The analysis of the different causes of mortality losses may also be performed in order not only to identify the main causes of mortality losses during the production cycle, but also to identify diseases patterns and factors associated with certain diseases that will allow understanding the main reasons for the outbreak development, as seen in the study made by Mardones et al. (2009) regarding the Chilean outbreak of ISAV. Definition of baseline mortality rates, and normal variation about this baseline, may allow companies and official regulators to identify situations in which intervention is called for, e.g. official inspection may be triggered if mortality exceeds a specific level dependent on production cycle stage. The baseline may also allow epidemiologists to identify emerging diseases and warn of potential future problems. As a result, strategic actions to control and avoid disease outbreaks may be developed as seen for instance the USA and Canada through the development of the surveillance plan for viral hemorrhagic virus (VHSV) IVb (Anonymous, 2010).

An interesting future study would be the use of more explanatory variables present in the database such as biomass, feed intake, growth rate, and temperature and production costs. These variables could be used to detect health and welfare problems and to perform more complex studies, including the industry performance and trends. 
In summary, this baseline benchmark method constitutes a first step towards further studies regarding mortality losses. It would be of great value for the industry if this benchmark tool was developed more extensively to the whole industry in the future. It would help to evaluate various aspects of management and production in relation to the best practices within a business. Moreover, it may also provide early indications of specific problems (Anonymous, 2009 c) and consequently, it might also be possible to find and develop early solutions for future problems of production.

\section{Acknowledgements}

This research was supported by Marine Scotland Science.

\section{References}

Anonymous (2009 a). A fresh start - the renewed strategic framework for Scottish aquaculture. The Scottish Government, Edinburgh. http://www.scotland.gov.uk/Publications/2009/05/14160104/0 Accessed on18th of February of 2010.

Anonymous (2009 b). Chilean salmon production forecasted to drop $40 \%$ this year. http://en.mercopress.com/2009/03/03/chilean-salmon-production-forecasted-to-drop40-this-year Accessed on $18^{\text {th }}$ of February of 2010.

Anonymous (2009 c). Sentinel farms in the UK trout industry. Project funded by SARFS. http://www.sarf.org.uk/Project\%20Final\%20Reports/SARF028FinalReport.pdf Accessed on18th of February of 2010.

Anonymous (2010). Viral hemorrhagic septicemia virus (VHSV IVb) risk factors and association measures derived by expert panel. Prev. Vet. Med. 94, 128-139.

Anonymous (2006). The Canadian Farmed Salmon Industry. Benchmark Analysis for the US Market. Agriculture and Agri-food Canada, Ottawa, Ontario.

http://www.ats.agr.gc.ca/can/4220-eng.pdf Accessed on18th of February of 2010.

Aunsmo, A.; Bruheim; T.; Sandberg, M.; Skjerve, E.; Romstad, S.; Larssen, R.B. (2008). Methods for investigating patterns of mortality and quantifying cause-specific mortality in sea-farmed Atlantic salmon Salmo salar. Dis. Aquat. Org. 81, 99-107. 
Brun, E.; Poppe T., Skrundland, A., Jarp, J. (2003). Cardiomyopathy syndrome in farmed Atlantic salmon Salmo salar: occurrence and direct financial losses for Norwegian aquaculture. Dis. Aquat. Org. 56, 241-247.

Bruno, D.W (2004). Changes in prevalence of clinical infectious pancreatic necrosis among farmed Scottish Atlantic, salmon, Salmo salar L., between 1990 and 2002. Aquaculture 235, 13-26.

Davidson, A.A. (2005). The use of baseline production data in order to benchmark New Zealand with key international trading partners. In: Manipulating pig production X. Proceedings of the Tenth Biennial Conference of the Australasian Pig Science Association (APSA), held in Christchurch, New Zealand, $27^{\text {th }}$ to $30^{\text {th }}$ November. http://www.cababstractsplus.org/abstracts/Abstract.aspx? AcNo=20063104330 Accessed on the 19th of February of 2010.

FAO, (2007). Aquaculture development. 2. Health management for responsible movement of live aquatic animals. FAO Technical Guidelines for Responsible Fisheries. No. 5, Suppl. 2. Rome, FAO. 2007. 31p.

Frost, A.R; Parsons, D.J.; Stacey, K.F.; Robertson, A.P.; Welch, S.K.; Filmer, D.; Fothergill, A. (2003). Progress towards the development of an integrated management system for broiler chicken production. Comp. Electron. Agric. 39, 227-240.

Frost, A.R; Schofield, C.P.; Beaulah, S.A.; Mottram, T.T.; Lines, J.A.; Wathes, C.M. (1997). A review of livestock monitoring and the need for integrated systems. Comp. Electron. Agric. 17, 139-159.

Geent, K.G.; Fleming, E.M.; Rutley, D.L.; Kemp, D.R. (2006). Farm benchmarking - the next level. In: Wools meets meat: tools for a modern sheep enterprise. Proceedings of the 2006 Australian Sheep Industry Cooperative Research Centre Conference, Orange, Australia. http://www.cababstractsplus.org/abstracts\%5C/Abstract.aspx? AcNo=20063181805 Accessed on the 19th of February of 2010.

Gustafson, L.L.; Ellis, S.K.; Bartlett, C.A. (2005). Using expert opinion to identify risk factors important to infectious salmon anaemia (ISA) outbreaks on salmon farms in Maine, USA, and New Brunswick, Canada. Prev. Vet. Med. 70, 17-28.

Hammel, K.L.; Dohoo, I.R. (2005). Mortalities patterns in infectious salmon anaemia virus outbreaks in New Brunswick, Canada. J. Fish Dis. 28, 639-650. 
Khade, A.S.; Metlen, S.K. (1996). An application of benchmarking in the dairy industry. Benchmarking for Quality Management and Technology 3, 31-41.

Mardones F.O., Perez A.M., Carpenter T.E. (2009). Epidemiological investigation of the reemergence of infectious salmon anaemia virus in Chile. Dis. Aquat. Org. 84, 105-114. Menzies, F.D.; McLoughlin, M.F.; Wheatley, S.B.; Goodall, E.A. (1996). Development of a computerized information retrieval system for Atlantic salmon, Salmo salar L., production. Aqua. Res. 27, 183-190.

Menzies, F.D.; Crockford, T.; Breck, O.; Midtlyng, P.J. (2002). Estimation of direct costs associated with cataracts in farmed Atlantic salmon (Salmo salar). Bull. Eur. Ass. Fish Pathol. 22, 27-32.

Nylund, A.; Wallace, C.; Hovland, T. (1993). The possible role of Lepeophtheirus salmonis (Kroyer) in the transmission of infectious salmon anemia. In: Boxshall GA, Defaye D (eds) Pathogens of wild and farmed fish: sea lice. Ellis Horwood Limited, Chichester, p $367-373$.

Parsons, D.J.; Green, D.M.; Schofield, C.P.; Whittemore, C.T. (2007). Real-time control of pig growth through an integrated management system. Biosyst. Eng. 96, 257-266.

Skall, H.F.; Olesen, N.J.; Mellergaard, S. (2005). Viral haemorrhagic septicaemia virus in marine fish and its implications for fish farming - a review. J. Fish Dis. 28, 509-529.

Stacey, K.F.; Parsons, D.J.; Frost, A.R.; Fisher, C.; Filmer, D.; Fothergill, A. (2004). An automatic growth and nutrition control system for broiler production. Biosyst. Eng. 89, 363-371.

Wheatly, S.B., McLoughlin, M.F., Menzies, F.D., Goodall, E.A. (1995). Site management factors influencing mortalities rates in Atlantic salmon (Salmo salar L.) during marine production. Aquaculture 136 195-207.

Vass, S. (2010). Scottish salmon farms reeling in new business. http://www.heraldscotland.com/business/markets-economy/scottish-salmon-farmsreeling-in-new-business-1.1008055 Accessed on 5th of March of 2010. 